\title{
Performance evaluation of setback buildings with open ground storey on plain and sloping ground under earthquake loadings and mitigation of failure
}

\author{
Rahul Ghosh $^{1} \cdot$ Rama Debbarma $^{1}$
}

Received: 25 May 2016/ Accepted: 27 January 2017/Published online: 14 February 2017

(C) The Author(s) 2017. This article is published with open access at Springerlink.com

\begin{abstract}
Setback structures are highly vulnerable during earthquakes due to its vertical geometrical and mass irregularity, but the vulnerability becomes higher if the structures also have stiffness irregularity in elevation. The risk factor of such structure may increase, if the structure rests on sloping ground. In this paper, an attempt has been made to evaluate the seismic performance of setback structures resting on plain ground as well as in the slope of a hill, with soft storey configuration. The analysis has been performed in three individual methods, equivalent static force method, response spectrum method and time history method and extreme responses have been recorded for open ground storeyed setback building. To mitigate this soft storey effect and the extreme responses, three individual mitigation techniques have been adopted and the best solution among these three techniques is presented.
\end{abstract}

Keywords Irregular construction - Setback - Stiffness · Slope $\cdot$ Soft storey

\section{Introduction}

Effective functional efficiency of structures along with attractive aesthetical appearance is mostly in demand in this modern civilisation. Therefore, there is popular and increasing demand for the construction of multi-storeyed

Rama Debbarma

ramadebbarma@gmail.com

Rahul Ghosh

rahulrazghosh@gmail.com

1 Department of Civil Engineering, National Institute of Technology Agartala, Tripura 799046, India setback buildings with soft storey i.e., open ground storey. This effort reduces the stiffness of the lateral load resisting system and setback configuration generates vertical irregularities in the structure. According to IS 1893 (Part 1): 2002, any storeys which have a lateral stiffness less than $70 \%$ of that of the storey immediately above, or less than $80 \%$ of the combined stiffness of the three storeys above, are called soft storeys. An extreme soft storey is one in which the lateral stiffness is less than $60 \%$ of that in the storey above or less than $70 \%$ of the average stiffness of the three storeys above. And if the lateral strength of a particular storey is less than $80 \%$ of that of the storey immediately above, it is called weak storey. Setback structure is the one with vertical geometric irregularity, where the horizontal dimension of the lateral force resisting system in any storey is more than $150 \%$ of that in adjacent storey. These structural irregularities are not acceptable from stability point of view, as recent earthquakes have proved the structural vulnerability during earthquakes. So, extensive research is required for achieving ultimate performance even with a poor configuration. All the structures during earthquakes are proved to be vulnerable but the structures with soft storey configuration i.e., structures with stiffness irregularity in elevation are found to be most vulnerable during earthquake. And the risk factor becomes much more if soft storeyed structures have also setback configuration in elevation. Scarcity of plain ground in hilly regions and urge of extracting natural beauty of hills, lead us to construct such irregular structures in the slopes of the hills also. Thus, the risk factor of those irregular structures increases abruptly as even the base of those structures becomes inclined at slope. This deadly combination of geometrical irregularity, mass irregularity, stiffness irregularity and torsional response makes the structures too much weak to survive during earthquake. Hence, it is important to study the responses of such buildings to make such buildings 
earthquake-resistant and prevent their collapse to save the loss of life and property. Murthy (2006) found that open ground storey buildings were highly vulnerable to shear generated during strong earthquakes and those were relatively flexible in the ground storey. Konakalla et al. (2014) studied the effect of vertical irregularities on multi-storeyed buildings under dynamic load using linear static analysis and observed torsional response due to vertical irregularity. Prashant and Kori (2013) performed a study on the building situated on hill slope $\left(27^{\circ}\right.$ with horizontal) to bring out the effect of soft storey on the response of structure. Birajdar and Nalawade (2004) studied the seismic response of three different configurations of buildings situated on sloping ground and found that stepback setback buildings were more suitable on sloping ground. Ghosh and Debbarma (2015) investigated the deficiency of soft storeyed structure in both linear static and linear dynamic method. They recommended the use of shear walls in the soft storey to mitigate its failure by increasing its stiffness and controlling its displacement and drift excellently. Ghosh and Debbarma (2016) studied the seismic vulnerability of soft-storeyed structures with plan irregularity, and to mitigate the structural failure, a solution was proposed by them. Halkude et al. (2013) performed response spectrum analysis (RSA) on two types of building frames namely step back frames and stepback and setback building frames on sloping ground. They found that step back and set back building frames were more suitable on sloping ground in comparison with step back frames. Kalsulkar and Rathod (2015) carried out response spectrum method of analysis on the step back frames and step back-set back frames on the sloping ground with varying number of bays. They found that step back setback frames were less vulnerable than step back frames and greater number of bays was better under seismic conditions. Arjun and Arathi (2016) studied the behaviour of $\mathrm{G}+3$ storied sloped frame building having step back-set back configuration for sinusoidal ground motion with different slope angles by performing response spectrum analysis. They observed that short column was affected more during the earthquake. Thombre and Makarande (2016) made comparison between sloping ground, with different slope and plain ground buildings in response spectrum method as per IS 1893-2000. They found that, on sloping ground, the displacement of building showed the same behaviour as of regular building but displacement's value reduced with the increment of slopes due to curtailment of column. Nagarjuna and Patil (2015) observed that short columns were affected more during the earthquake, and for construction of the building on sloping ground, the stepback setback building configuration was suitable, along with shear walls at the corner of the building. Kumar et al. (2014) performed seismic analysis of a $\mathrm{G}+4$ storey RCC building on varying slope angles and compared with the same on the flat ground using linear static method. They observed that the footing columns of shorter height attract more forces, because of a considerable increase in their stiffness, which in turn increased the shear and bending moment significantly. Khadiranaikar and Masali (2014) reviewed number of studies and found that most of the studies agree that the buildings resting on sloping ground has higher displacement and base shear compared to buildings resting on plain ground, and the shorter column attracts more forces and undergo damage when subjected to earthquake. Step back building could prove more vulnerable to seismic excitation.

\section{Details of building and modelling of structure}

A residential setback building resting on plain and sloping ground has been analysed. The building is symmetric in plan and elevation up to the third storey on plain ground, but setback is located in the fourth and fifth floors. The building becomes highly unsymmetrical, when it is considered on $45^{\circ}$ sloping ground of a hill. All the details related to structure, which are taken as per Ghosh and Debbarma (2016), are provided here.

Seismic design data are as follows:

Zone factor (Z): 0.36 , soil type: medium soil, damping ratio: $5 \%$, frame type: special moment-resisting frame (SMRF), response reduction factor (R): 5, and importance factor (I): 1 .

Material properties are as follows:

Unit weight of concrete: $25 \mathrm{kN} / \mathrm{m}^{3}$, Unit weight of Infill walls: $21.2068 \mathrm{kN} / \mathrm{m}^{3}$, characteristic strength of concrete: $30 \mathrm{MPa}$, characteristic strength of steel: $415 \mathrm{MPa}$, compressive strength of masonry walls: $4.1 \mathrm{MPa}$, modulus of elasticity of masonry walls: $2300 \mathrm{MPa}$, characteristic strength of steel tube: $345 \mathrm{MPa}$.

Details of structural elements are as follows:

Beam: $250 \mathrm{~mm} \times 300 \mathrm{~mm}$, column: $350 \mathrm{~mm} \times 350$ $\mathrm{mm}$, slab thickness: $150 \mathrm{~mm}$, wall thickness: $250 \mathrm{~mm}$, parapet height: $1000 \mathrm{~mm}$, shear wall thickness: $200 \mathrm{~mm}$, single strut width: $1060 \mathrm{~mm}$, steel tube: $550 \mathrm{~mm} \times$ $550 \mathrm{~mm} \times 100 \mathrm{~mm}$.

The types of load considered during the design are dead loads of beams, columns, slab, wall weight (WL), live load of 3 at floors and $1.5 \mathrm{kN} / \mathrm{m}^{2}$ at roof, mass source $(1.0$ $\mathrm{DL}+1.0 \mathrm{WL}+0.25 \mathrm{LL})$.

The modelling of the structure includes the modelling of structural elements like column, beam, slab, base conditions, joint conditions, and non-structural elements like masonry walls (Ghosh and Debbarma 2016). The models are created and analysed in integrated building design software ETABS 2015 version 15.0.0.

Columns are modelled as two-nodded rectangular continuous vertical line elements and beams are modelled as same but as horizontal elements. The columns are taken to 
be square to keep the discussion focused only on the soft storey effect, without being distracted by the issues like orientation of columns. The cross-sectional areas of the beams are kept smaller than that of columns to justify strong-column weak-beam theory. Slabs are modelled as four-nodded rectangular shell area elements. Base conditions are made fixed by restraining all the degrees of freedom of the each joints of the base. Joint diaphragms in all the joints of the structure are made as fixed or flexible depending upon the condition to make all the joints act as a single unit containing the nodes of beam column and slabs together on that joint.

In this paper, macro-modelling approach has been adopted for modelling the walls which is easy to model, and analysis can be done faster and also gives good results. The lengths of the struts are the same as the diagonal length of the wall. Width of the strut has been taken as one-fourth of the diagonal length of the wall and thickness is the same as the thickness of wall; all other properties of the strut are the same as the properties of masonry wall Kaushik et al. (2007). The struts are modelled as two-nodded pinned line elements.

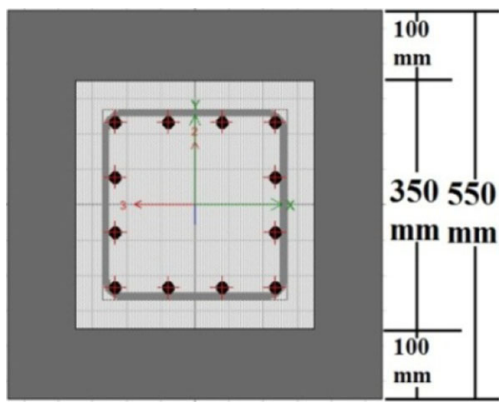

Fig. 1 Cross-section of RCFSTC
For reinforced concrete-filled steel tube columns (RCFSTC), hollow square steel tubes of dimension $550 \mathrm{~mm} \times 550 \mathrm{~mm}$ and thickness of $100 \mathrm{~mm}$ are used as shown in Fig. 1. The hollow tube is filled with the same RC column of $350 \mathrm{~mm} \times 350 \mathrm{~mm}$, which has the same grade of concrete (M30) and same distribution of reinforcement of other $350 \mathrm{~mm} \times 350 \mathrm{~mm}$ columns.

\section{Analysis methods}

In this paper, all the models are analysed both in linear static method which is known as equivalent static force method (ESFM) and linear dynamic method which is response spectrum method (RSM) and time history method (THM). ESFM analysis and RSM analysis are done and results are compared to study the seismic behaviour of the structures. In modal analyses, mode shapes are generally obtained in normalized form, and thus, the results of response spectrum method need to be properly scaled. In the present study, the scaling has been done by equating the base shear obtained from ESFM to that obtained from RSM. In ESFM analysis, different load combinations suggested by different codes have been taken and the combination 1.5 ( $\mathrm{DL} \pm \mathrm{EL}$ ) has given the most of the effect. Time history analysis is done using real earthquake data of Kobe earthquake.

\section{Models analysed}

To explore the different responses of setback building and regular building, fundamental bare frame models of these buildings are analysed. Later on, to include the soft storey effect on setback structure, the fully infilled setback model

Table 1 Details of analysed models

\begin{tabular}{lll}
\hline Description of the models & Notations \\
\hline Regular bare frame on plain ground & R0 & S0 \\
Setback bare frame on plain ground & S1 \\
Fully infilled setback frame on plain ground & S2 \\
Setback building with OGS, but other storeys infilled on plain ground & S3 \\
Same as model S2 but only the core panels of OGS are infilled with shear wall & S4 \\
Same as model S2 but only the central panels of the four peripheral sides of OGS are infilled with shear wall & S6 \\
Same as model S2 but OGS columns are designed by magnification factor of 2.5 & h0 \\
Same as model S2 but OGS columns are replaced by RCFSTC & h1 \\
Setback bare frame on sloping ground & h2 \\
Fully infilled setback frame on sloping ground & h3 \\
Setback building with OGS but other storeys infilled on sloping ground & h4 \\
Same as model h2 but OGS columns are designed by 2.5 times of the ground storey moment and shear force & \\
Same as model h2 but OGS columns are replaced by RCFSTC & \\
\hline
\end{tabular}


and OGS setback models are adopted. After that, different modification techniques are implemented on the OGS setback model, to overcome the stiffness deficiency and improve structural response, due to setback effect along with soft storey configuration. The responses of different setback models are also investigated over the sloping ground. Name and description of models are given in Table 1. and shown in Fig. 2.

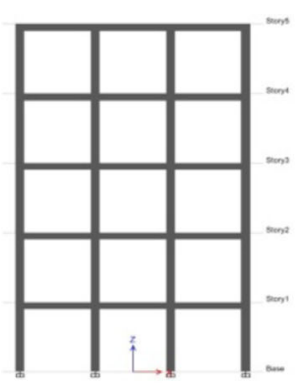

(a)

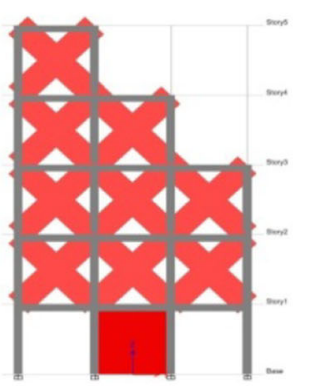

(e)

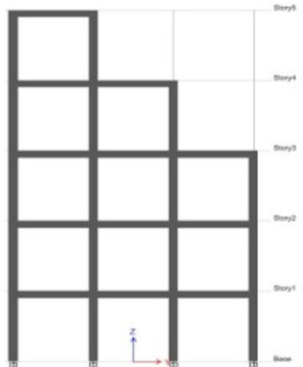

(b)

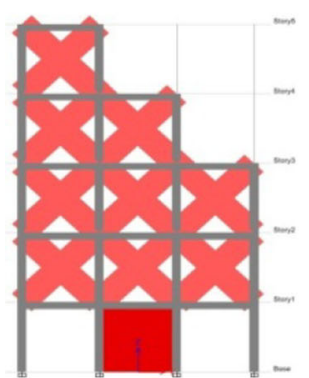

(f)

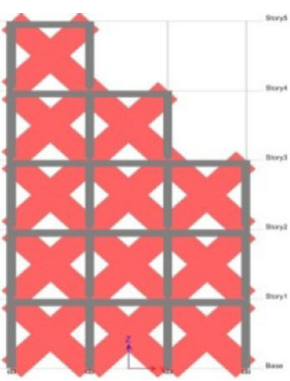

(c)

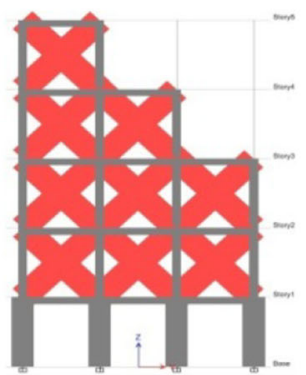

(g)

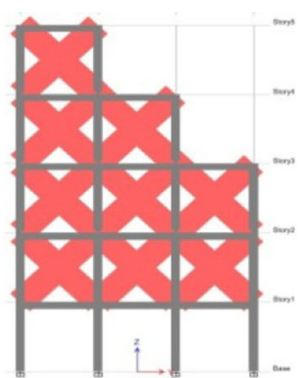

(d)

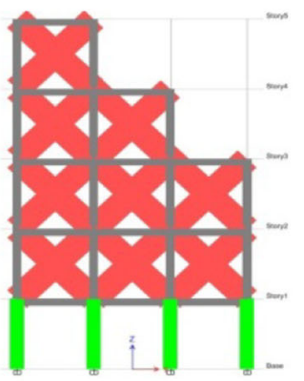

(h)

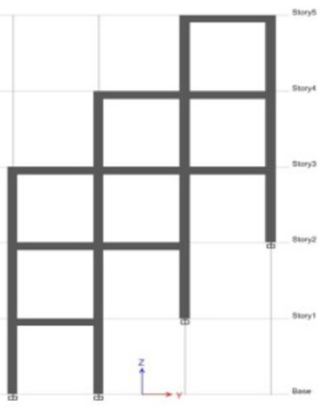

(i)

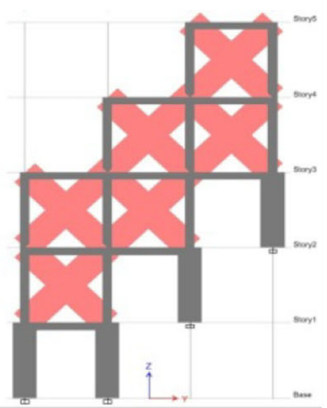

(l)

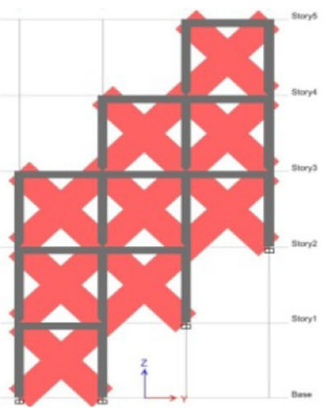

(j)

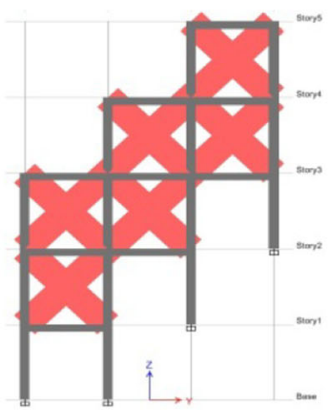

(k)

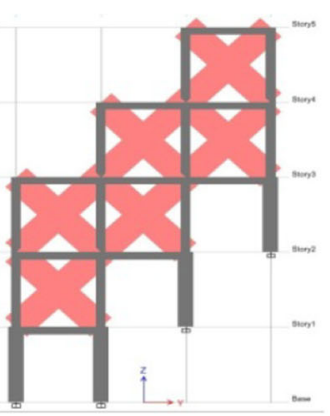

(m)

Fig. 2 Images of models, a Model R0, b Model S0, c Model S1, d Model S2, e Model S3, f Model S4, g Model S5, h Model S6, i Model h0, j Model h1, k Model h2, l Model h3, m Model h4 


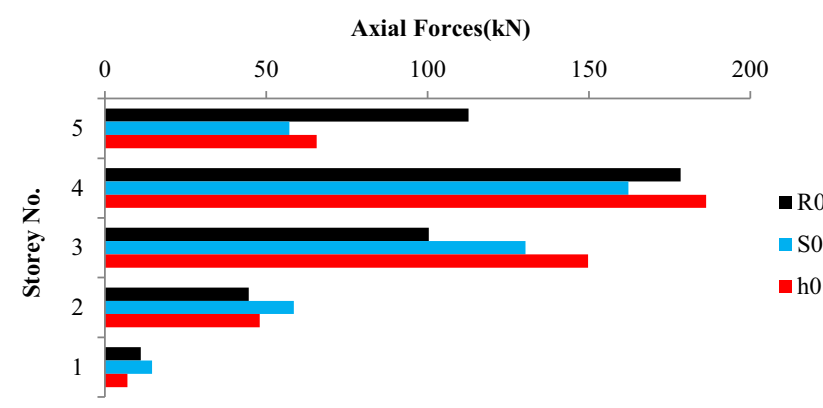

Fig. 3 Axial force distribution along the storey height

\section{Results and discussion}

The bare frame models of three different configurations, such as regular configuration on plain ground, setback configuration on plain ground and setback configuration on sloping ground are compared to study the basic difference between these structures. Later on, the effect of soft storey configuration on the setback building resting on slope is studied along with their collapse prevention techniques.

From Fig. 3, the difference between axial force distribution along the storey height of regular and setback buildings on plain ground is observed. It is noticed that, up to the third storey, where setback is absent, the axial forces of model S0 are more than that of model R0. However, in the fourth and fifth storey, where setback is present with a ratio of 1.5 and 2, the axial forces become lesser in the model S0 in comparison with the model $\mathrm{R} 0$. This reduction of axial forces on the fourth and fifth storeys of model S0 has taken place only due to setback effect. But in the model h0, the amount of axial forces is higher than the model S0 in maximum storeys as the model is resting on inclined base.

After analysis, the fundamental difference in terms of displacement profiles between the bare frames of different configurations is shown in Figs. 4 and 5. The notations used in the graphs are as follows:

$\mathrm{R} 0 \mathrm{X}=$ Regular model on plain ground at $\mathrm{X}$ direction,

SOXT $=$ Flexible side of setback model on plain ground at $\mathrm{X}$ direction,

SOXS = Stiffer side of setback model on plain ground at $\mathrm{X}$ direction,

h0XU $=$ Uphill side of setback model on sloping ground at $\mathrm{X}$ direction,

h0XD $=$ Downhill side of setback model on sloping ground at $\mathrm{X}$ direction,

$\mathrm{S} O \mathrm{Y}=$ Setback model on plain ground at $\mathrm{Y}$ direction, $\mathrm{VOY}=$ Regular model on plain ground at $\mathrm{Y}$ direction, $\mathrm{h} 0 \mathrm{Y}=$ Setback model on sloping ground at $\mathrm{Y}$ direction.
From Fig. 4, it is seen that, except model R0, in all other models, the displacement has taken place in both orthogonal directions ( $\mathrm{X}$ and $\mathrm{Y}$ directions) as the centre of mass and the centre of rigidity of those models do not coincide due to irregularity; as a result, the twisting of the structure in terms of displacement in the minor direction of force is obvious. Differential movement of the either sides of the structures in the direction of force has been recorded for all the models except model R0; the taller sides of the structure displace more than the shorter sides. The taller side of the structure has columns longer than the columns of the shorter side. Due to this reason, the taller side behaves more flexible than the shorter side under the same amount of force. The displacement profile of flexible side of S0 is even larger than that of $\mathrm{R} 0$, which reflects the serious condition of setback buildings during earthquake. The model h0, which is setback on sloping ground, has the same heights on both the sides, but the downhill side displaces more than the uphill side. The displacements of the either sides of model h0 in $\mathrm{X}$ direction as well as the $\mathrm{Y}$ directional displacement also has been counted lesser compared to other models.

It is observed that in both the methods, the amount of bending moment in every column of each individual storey in model R0 is almost similar. Maximum bending moment is at GS columns and the value of bending moment reduces with the increment of storey height in model R0. But in the model S0, within a particular storey, the columns of the taller side of building are subjected to higher bending moment, compared to the columns of shorter side of the building. This might be due to involvement of higher mass in taller side of building. Interestingly, in the model h0, despite having the same height on either sides of the building, huge variation of column bending moment has been recorded within a particular storey. In the model h0, the columns of the higher level of the slope are subjected to more bending moment compared to the columns at lower level of the slope; so, these columns on the higher level of slope need special attention.

The effect of inclusion of soft storey configuration on the setback building resting on sloping ground is investigated next.

\section{Base shear}

The base shear is a function of mass and stiffness of the structure; therefore, except the bare frame model, in all other models, the base shear has been increased due to the stiffness and mass provided by the infilled walls, and increased column sections and addition of steel tubes. Base shears of the setback models on plain and sloping ground are shown in Fig. 6. 
Fig. 4 Displacement profiles of models R0, S0, V0 and h0 a of flexible side at $\mathrm{X}$ direction in RSM, $\mathbf{b}$ of flexible side at $\mathrm{X}$ direction in ESFM, $\mathbf{c}$ of stiff side at $\mathrm{X}$ direction in RSM, $\mathbf{d}$ of stiff side at $X$ direction in

ESFM, e at $Y$ direction in RSM, $\mathbf{f}$ at $\mathrm{Y}$ direction in ESFM

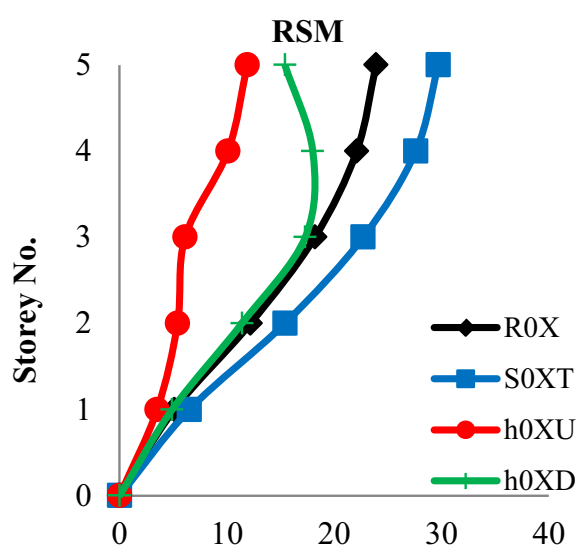

Displacement in X Direction (mm)

(a)

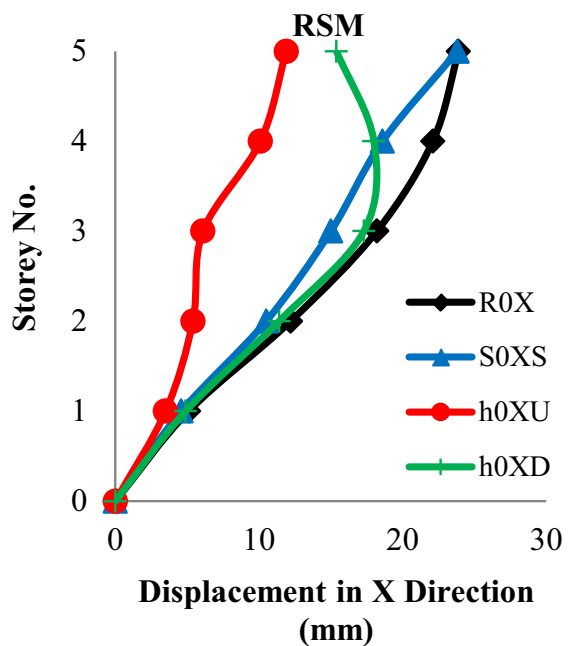

(c)

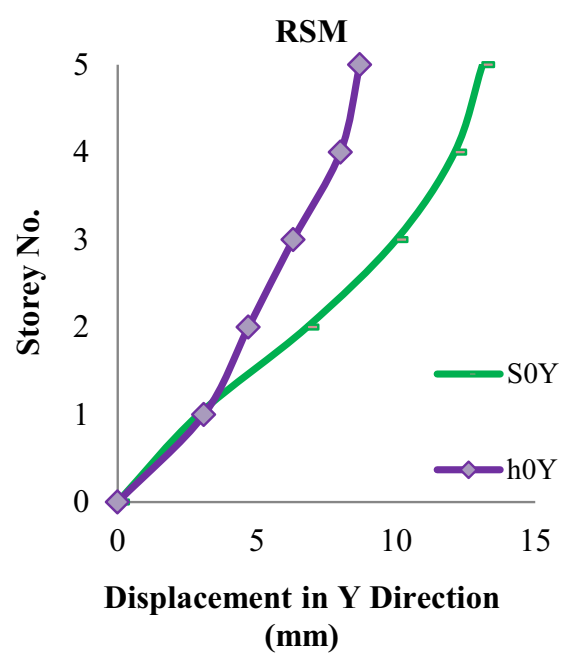

(e)

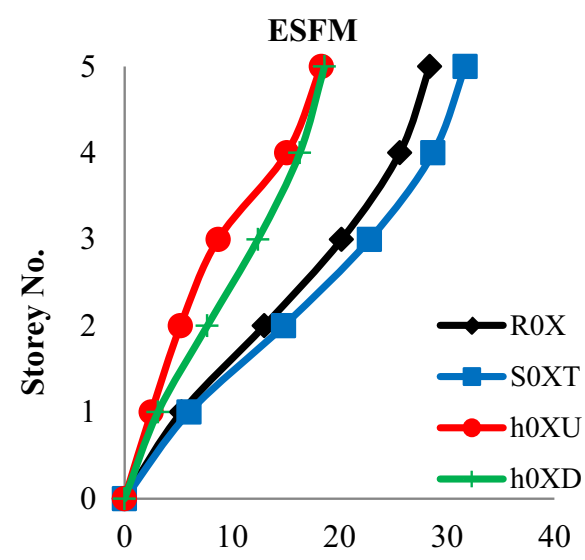

Displacement in X Direction (mm)

(b)

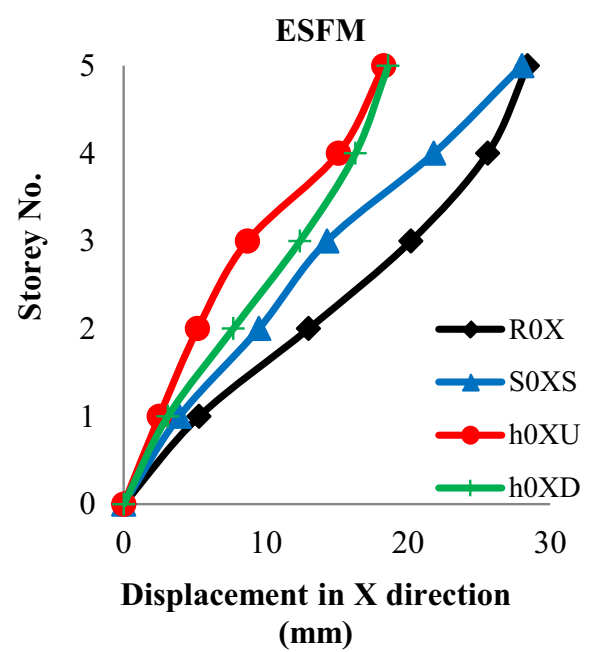

(d)

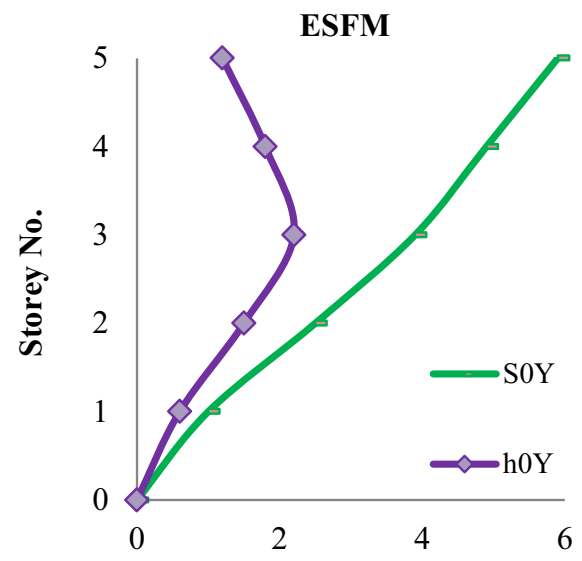

Displacement in $\mathrm{Y}$ direction (mm)

(f) 
Fig. 5 Column bending moments of a model R0 in RSM, b model R0 in ESFM, c model S0 in RSM, $\mathbf{d}$ model S0 in ESFM, e model h0 in RSM and $\mathbf{f}$ model h0 in ESFM

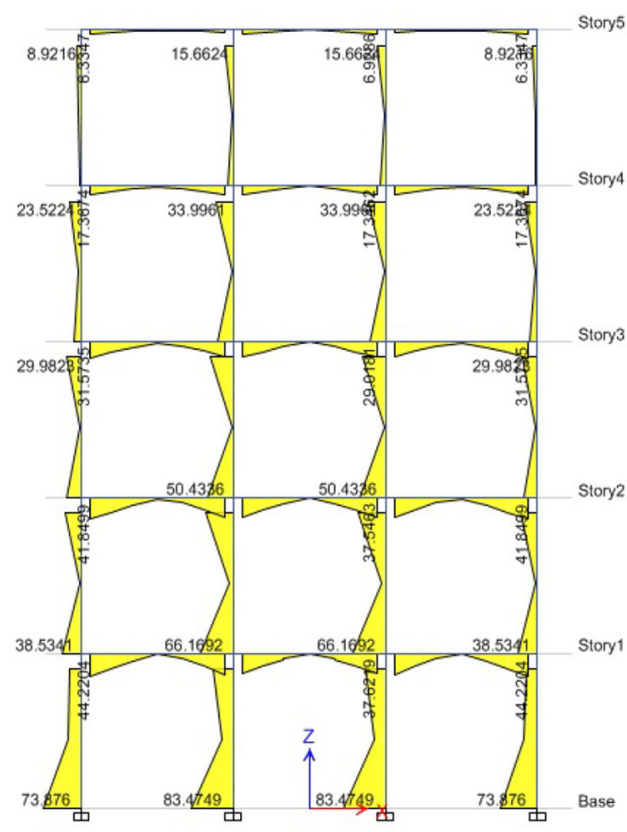

(a)

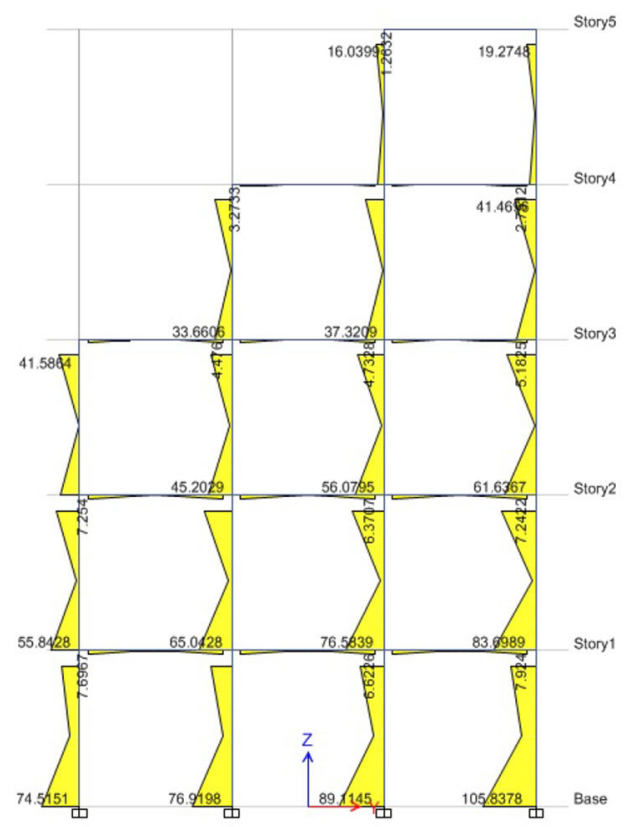

(c)

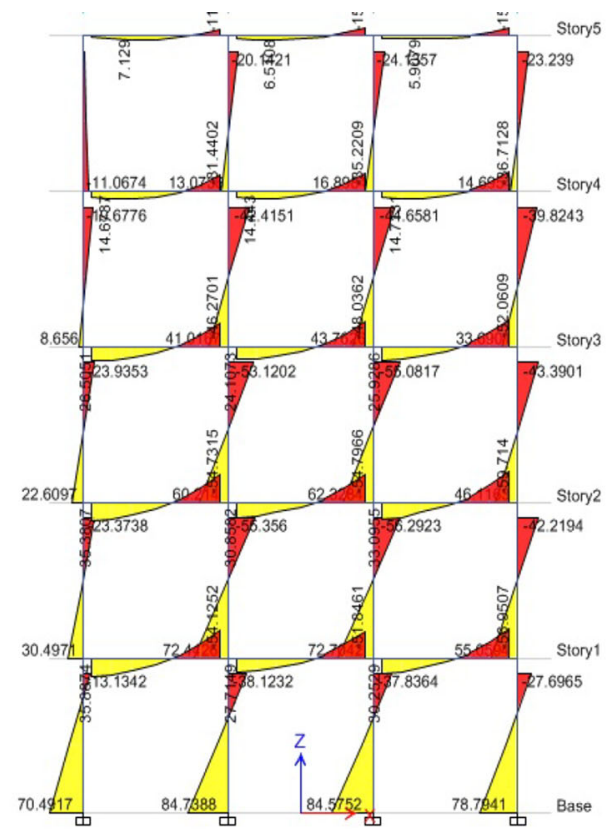

(b)

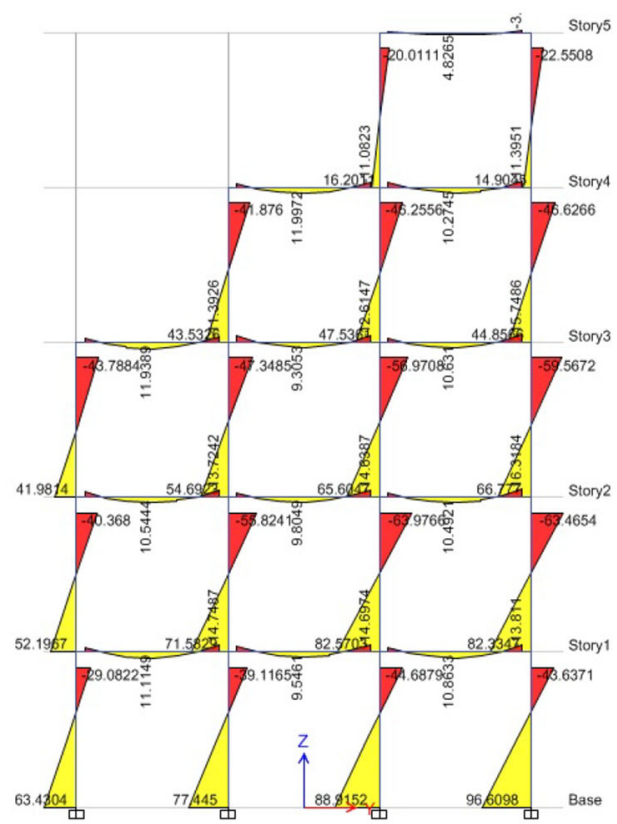

(d)

\section{Storey stiffness}

The stiffness of a particular storey is the total stiffness provided in the storey by its column, walls, and lateral load resisting systems. The stiffness of each storey for every model in both the methods is shown in Fig. 7. From
Fig. 7a, b, it is noticed that the nature of stiffness variation along the storey heights in both the methods is similar. Model S2 having an OGS at bottom storey shows that the OGS has very less stiffness of the immediate upper storey in both the methods. So, this model exhibits soft storey effect without any doubt, which is most vulnerable 


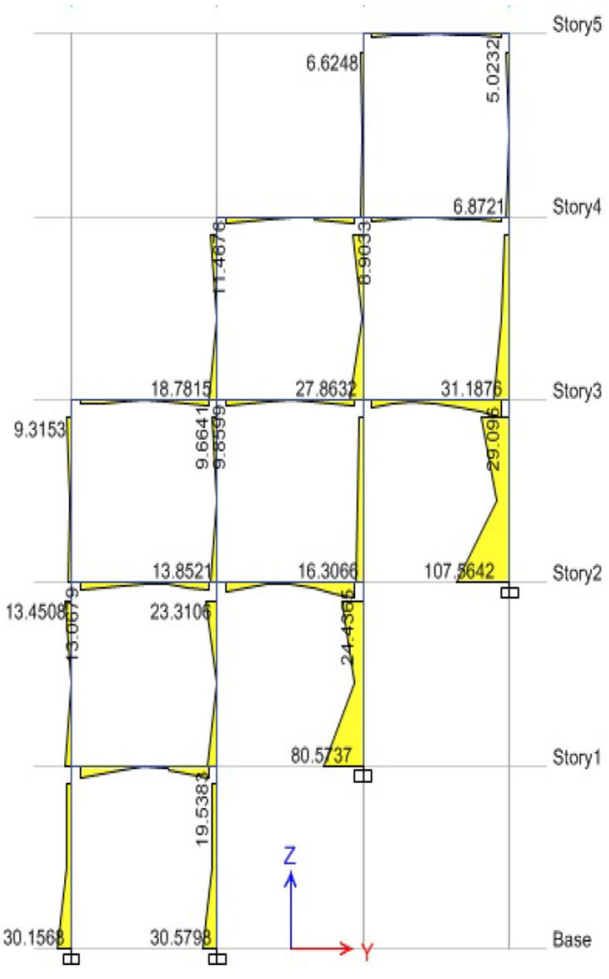

(e)

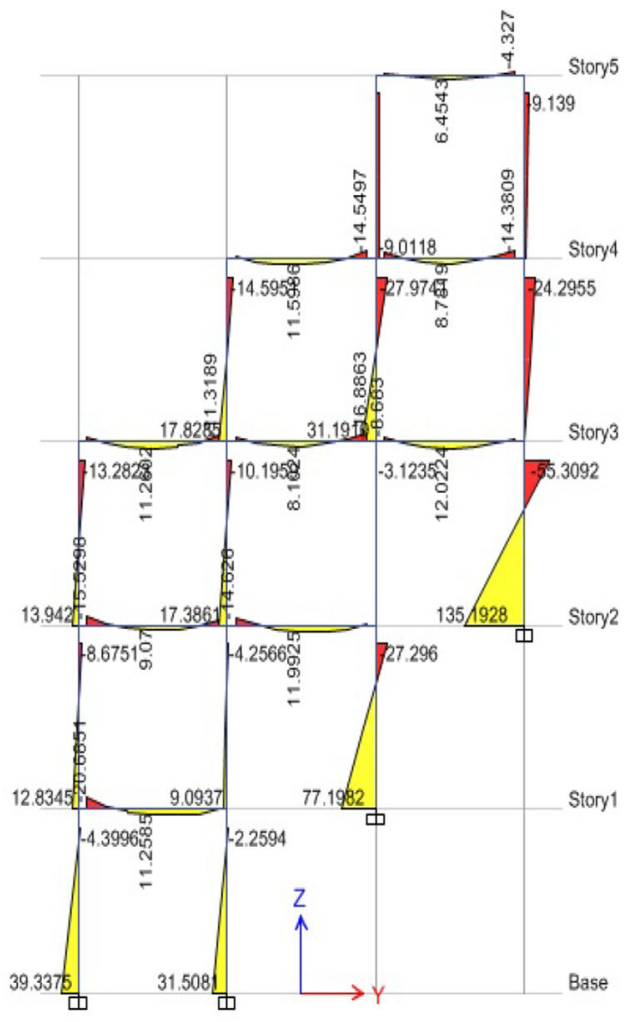

(f)
Fig. 5 continued

Fig. 6 Base shear of all the setback models a resting on plain ground and $\mathbf{b}$ resting on slope

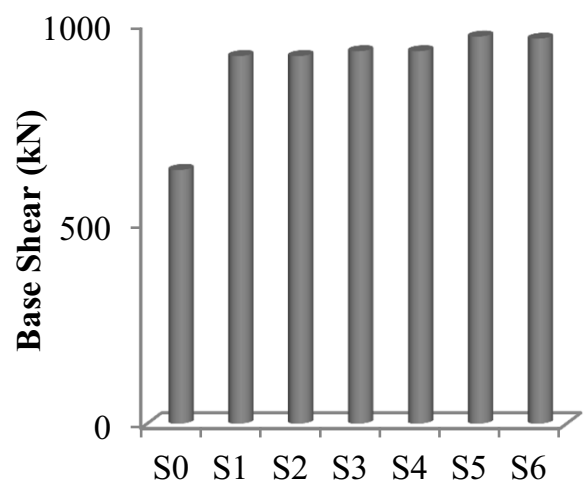

(a)

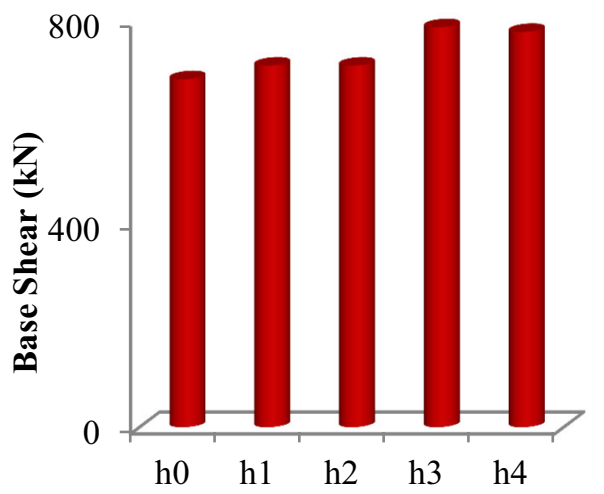

(b) during earthquake. To overcome this problem, shear walls are introduced on the next models S3 and S4, OGS columns are designed as 2.5 times of OGS moment and shear force in model S5, and RCFSTC are placed in place of regular RC columns of OGS in model S6. The stiffness percentage of the ground storey (GS) with respect to immediate upper storey is shown in Table 2. For the setback buildings resting on slope also, it is noticed that model h2 having an OGS at bottom storeys along the slope shows very less stiffness in both methods from Fig. 7c, d. The maximum deficiency of stiffness has been recorded at storey No. 1 and storey No. 3 of the model h2, which exhibits soft storey effect, as the stiffness percentage is lesser than $70 \%$ on those storeys. To increase 
Fig. 7 Variation of storey stiffness of a setback models resting in plain ground in RSM, b setback models resting in plain ground in ESFM, c setback models resting in sloping ground in RSM and d setback models resting in sloping ground in ESFM

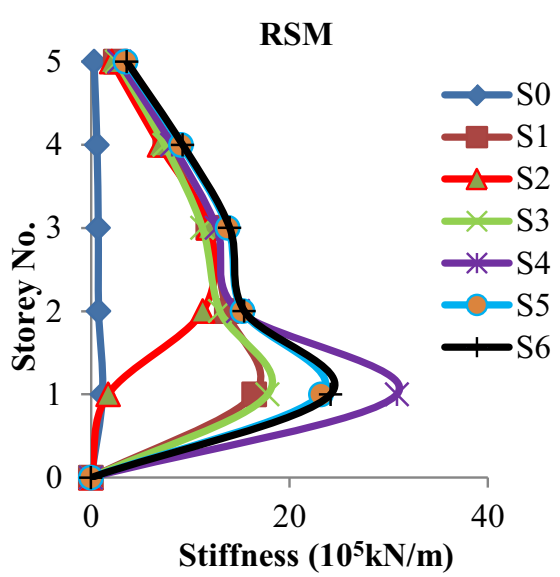

(a)

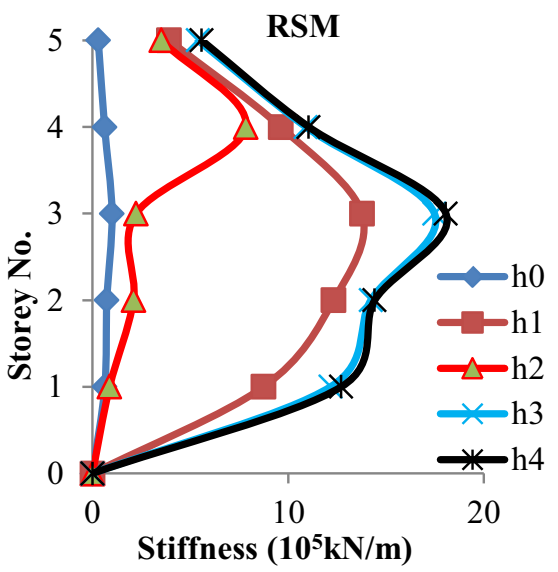

(c)

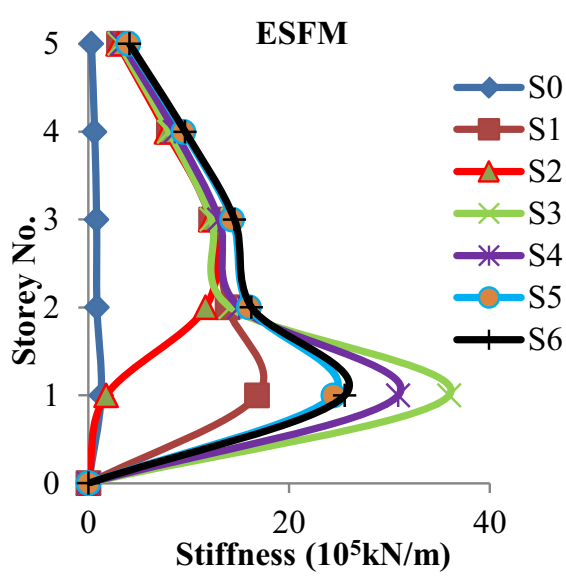

(b)

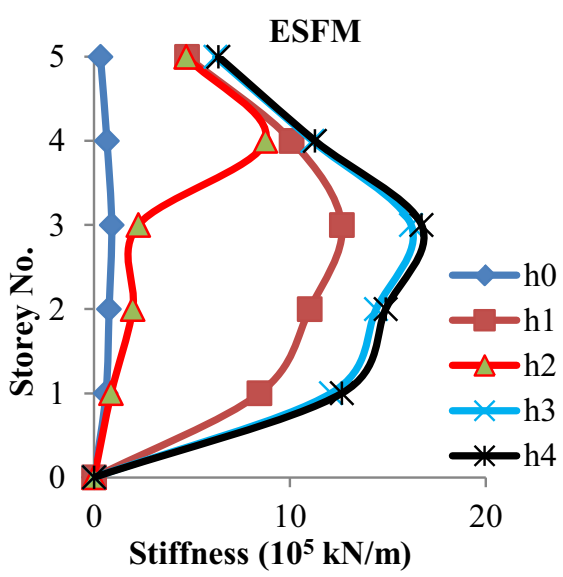

(d)
Table 2 GS stiffness percentage with respect to immediate upper storey

\begin{tabular}{llllllll}
\hline Models & S0 & S1 & S2 & S3 & S4 & S5 & S6 \\
\hline RSM & 152.44 & 120.09 & 15.23 & 137.17 & 207.66 & 151.65 & 156.27 \\
ESFM & 150.1 & 121.13 & 15.18 & 253.85 & 205.5 & 152.52 & 157.1 \\
\hline
\end{tabular}

stiffness, OGS columns are designed as 2.5 times of GS moment and shear force in model $\mathrm{h} 3$ and RCFSTC are placed in place of regular RC columns of OGS in model h4. The stiffness percentage of the OGS at storey No. 1 and storey No. 3 with respect to immediate upper storeys is shown in Table 3. So, the results show that introduction of shear walls, designing OGS columns as 2.5 times of OGS moment and shear force and introduction of RCFSTC in place of regular RC columns of OGS, effectively mitigate the problem of stiffness deficiency of soft storey by increasing the stiffness percentage of OGS well above the $70 \%$ of immediate upper storeys.

\section{Storey displacements}

Storey displacement is calculated for all the setback models along the direction of force and results are shown in Fig. 8 . GS displacement has been recorded maximum for the model S2 and h2 due to lesser stiffness caused by the absence of infill walls in that storey.

The study of setback models without infill (h0) and with infill (h1) on slopes shows that, the displacement control of model $\mathrm{h} 1$ on an average is $13-14$ times more than the model h0, due to introduction of infill walls. Bare frame models and fully infilled models are practically not 
Table 3 GS stiffness percentage with respect to immediate upper storey

\begin{tabular}{llrrrrr}
\hline Models & & \multicolumn{1}{c}{ h0 } & \multicolumn{1}{c}{ h1 } & h2 & \multicolumn{1}{c}{ h3 } & \multicolumn{1}{c}{ h4 } \\
\hline RSM & Storey no. 1 & 85.7 & 70.9 & 41.8 & 85.5 & 88.2 \\
& Storey no. 3 & 161.2 & 143.1 & 28.4 & 160.2 & 163.3 \\
ESFM & Storey no. 1 & 79.2 & 76.7 & 44.2 & 83.9 & 84.9 \\
& Storey no. 3 & 137.1 & 125.3 & 25.8 & 145.2 & 148.1 \\
\hline
\end{tabular}

preferred, but the remaining models where OGS is modified by three techniques show very good displacement control, and the displacement control capacities of all the techniques are also almost the same.

\section{Storey drift}

Inter-storey drift is the relative displacement between the adjacent floors per unit storey height in the direction of force. The results are shown in Fig. 9.

The results in both RSM and ESFM are similar in nature, although their values vary depending on their modelling and analysis method. Models S0 and h0 show maximum storey drift for all the storeys in both the methods except GS. GS drift is maximum for the models $\mathrm{S} 2$ and h2 due to stiffness. Model h2 is resting on slope at an inclined base; so, due to lesser stiffness of storey No. 3, high drift is also recorded there. The remaining models where OGS is modified by different techniques show very less inter-storey drifts.

\section{Torsion}

Torsion arises from the eccentricity in a building, when the centre of mass of the building does not coincide with its centre of rigidity. If there is torsion, the building will rotate about its centre of rigidity due to torsional moment about the centre of structural resistance. As the structure is a setback building as well as it is resting on sloping ground, therefore, it is irregular in vertical and horizontal planes in terms of mass, stiffness, and layout. As a result of this, the torsional response is recorded and storey rotation about vertical $(Z)$ axis is shown in Fig. 10. Maximum torsional response has been recorded for the bare frame models S0 and h0. It is noticed that torsional
Fig. 8 Variation of storey displacements in the major direction of force ( $\mathrm{X}$ direction) of all the setback models, a on plain ground in RSM, $\mathbf{b}$ on plain ground in ESFM, $\mathbf{c}$ on slope in RSM and $\mathbf{d}$ on slope in ESFM

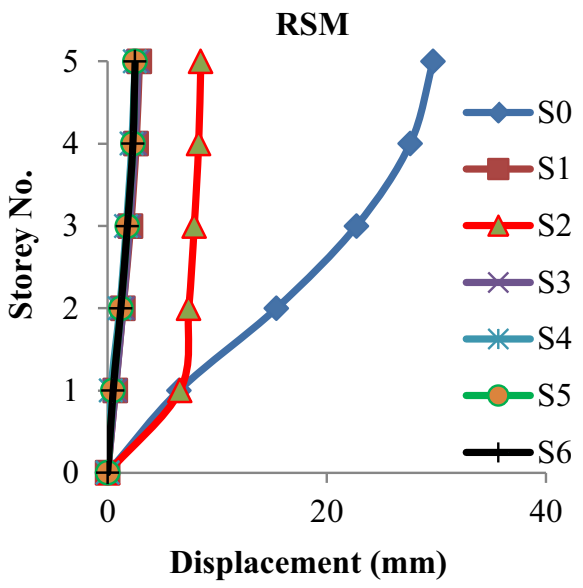

(a)

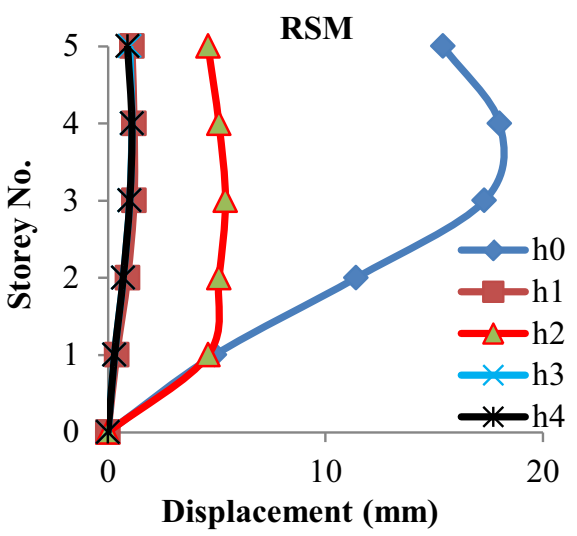

(c)

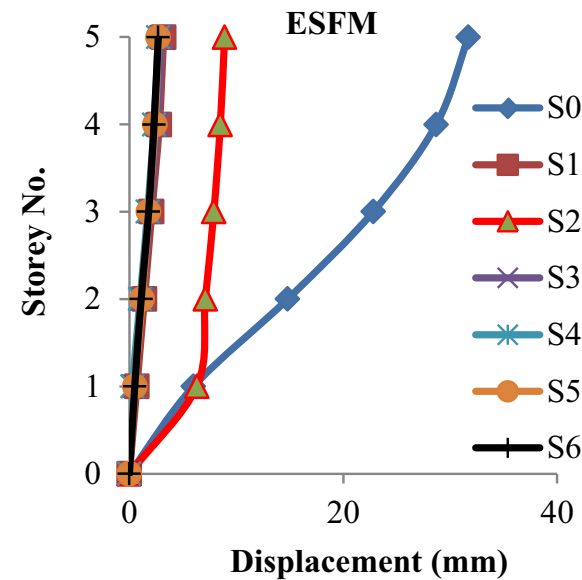

(b)

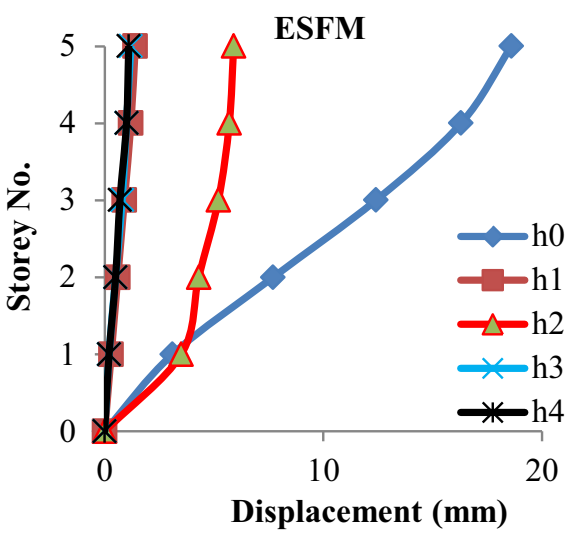

(d) 
Fig. 9 Variation of storey drift in the major direction of force (X direction) of all the setback models, $\mathbf{a}$ on plain ground in $\mathrm{RSM}, \mathbf{b}$ on plain ground in ESFM, $\mathbf{c}$ on slope in RSM and d on slope in ESFM

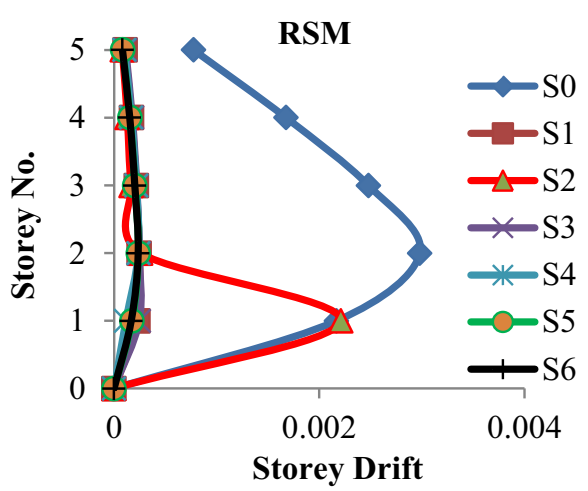

(a)

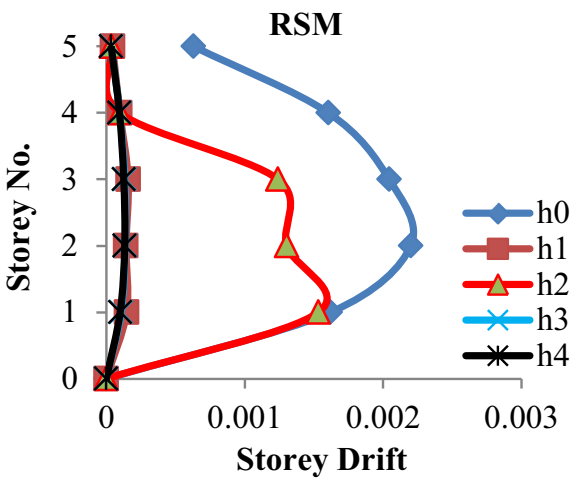

(c)

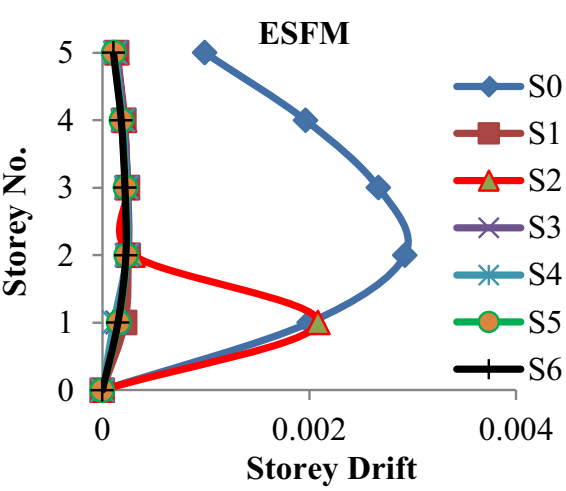

(b)

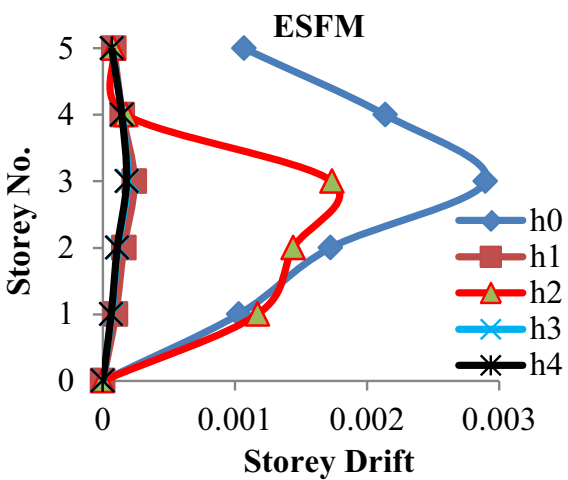

(d) response of model h0 is 1.5-3 times less than the model S0, and after introduction of the infill walls, the torsional response in the model $\mathrm{h} 1$ is further reduced by $13-15$ times of the model ho.

\section{Time history results}

Time history analysis is done using real earthquake data of Kobe earthquake. As for the setback models resting on plain ground, the extreme responses have been recorded for storey No. 1 (GS) of OGS model S2 and response control has been excellent in models S3, S4, S5 and S6; so, time history analysis is done for these models only. And for the setback models resting on sloping ground, extreme responses have been recorded for OGS model h2 and response control has been excellent in models $h 3$ and $h 4$; so, time history analysis is done for these models only. The results are shown in Figs. 11 and 12, in terms of GS displacement and torsion.

Time history results also reveal the vulnerability of softstoreyed structure, as the torsion and GS displacement of the OGS models are the maximum. The techniques applied in remaining models have been excellent in displacement and torsion control of OGS.

\section{Conclusion}

In this paper, the seismic response of setback buildings resting on plain and sloping ground along with soft storey at ground level under earthquake force has been analysed in two different methods, linear static method (ESFM) and linear dynamic method (RSM and THM). Moreover, the extreme vulnerability has been assessed when OGS is considered in these structures. Orthogonal movement under unidirectional force has been recorded for the setback buildings. These structures also reflect differential movement of either sides of the structure, as the taller side moves more than the shorter side along the direction of force. Due to the variation of mass, stiffness and geometry of the setback building, the twisting of the structure also takes place. The columns of the setback buildings at the higher level of the slopes are subjected to higher bending moments; so, special measures should be taken during their 
Fig. 10 Variation of torsional response of all the setback models, $\mathbf{a}$ on plain ground in $\mathrm{RSM}, \mathbf{b}$ on plain ground in ESFM, $\mathbf{c}$ on slope in RSM and d on slope in ESFM

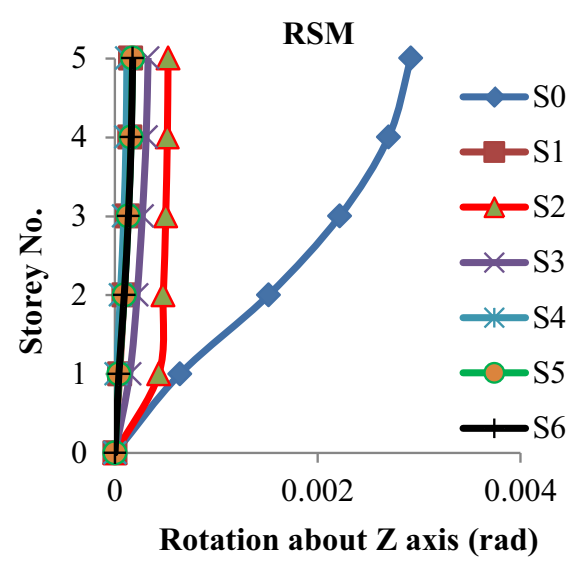

(a)

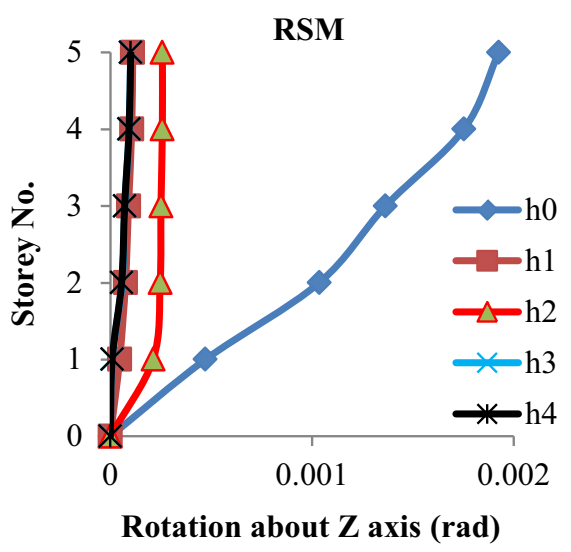

(c)

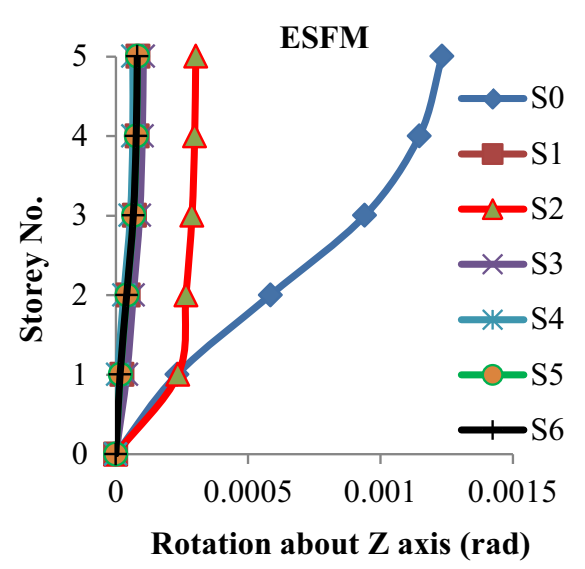

(b)

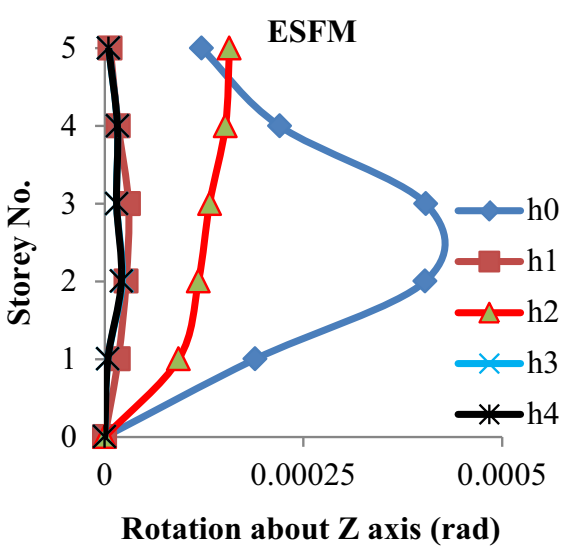

(d) design and construction. The stiffness of OGS model on setback building abruptly decreased due to absence of infill walls and is seriously effected under earthquake loading as its responses are much more than the other models. As the fully infilled models cannot serve the OGS purpose, the OGS models are further modified using shear walls, magnifying the OGS columns as 2.5 times of storey forces and replacing the OGS columns by RCFSTC. OGS structures with these three techniques behave excellently under earthquake loadings, even better than fully infilled model. The ground storey stiffness of these models using these three techniques is more than that required to overcome soft storey effect of OGS model, and upper storey stiffness of these models also gets better. The storey displacement, drift, and torsion control are found to be excellent by these three techniques, and the controlling capacities of these techniques are also almost the same. Spreader construction of shear wall shows better torsional control, but the problem with shear wall is that shear walls are blocking accesses in OGS, thus reducing the functional efficiency of the structure and stiffness is concentrating at some particular locations of the structure. The possibility of generation of plastic hinges becomes prominent in the model where OGS columns are magnified with 2.5 times of storey forces. There is a sudden abrupt change of the RC column section at the junctions of OGS columns and immediate upper storey columns. Both these problems are effectively solved using RCFSTC in the OGS, as the model with RCFSTC is not blocking any access in OGS, stiffness is uniformly distributed over the whole base of the structure and $\mathrm{RC}$ column section is also not changing at the junction. So, RCFSTC in OGS has been found as the most effective solution for collapse prevention of setback building with soft storey configuration at ground level during earthquakes. This paper proposes the use of RCFSTC in the place of ordinary RC column at OGS of the multi-storeyed setback buildings with soft storey configuration at ground level in both plain and sloping ground. This work is done considering seismic zone $\mathrm{v}$ and medium type of soil only; so, the same work can be continued considering other 
Fig. 11 Variation of GS displacement with respect to time, $\mathbf{a}$ on plain ground in $\mathrm{X}$ direction, $\mathbf{b}$ on plain ground in $\mathrm{Y}$ direction, $\mathbf{c}$ on slope in $\mathrm{X}$ direction and $\mathbf{d}$ on slope in $\mathrm{Y}$ direction

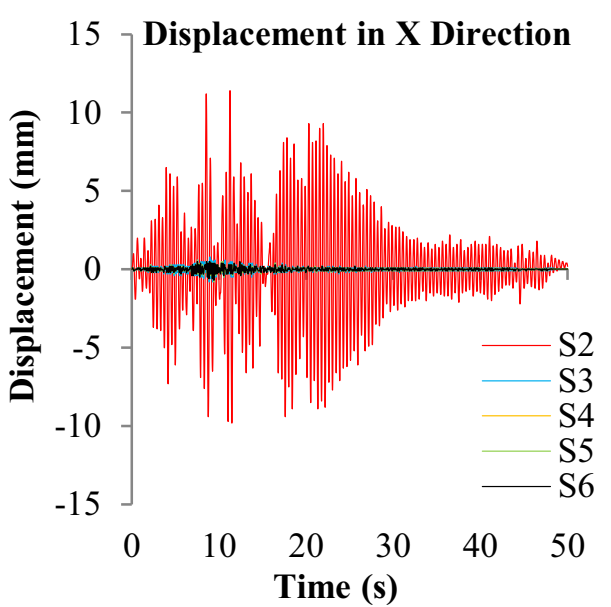

(a)

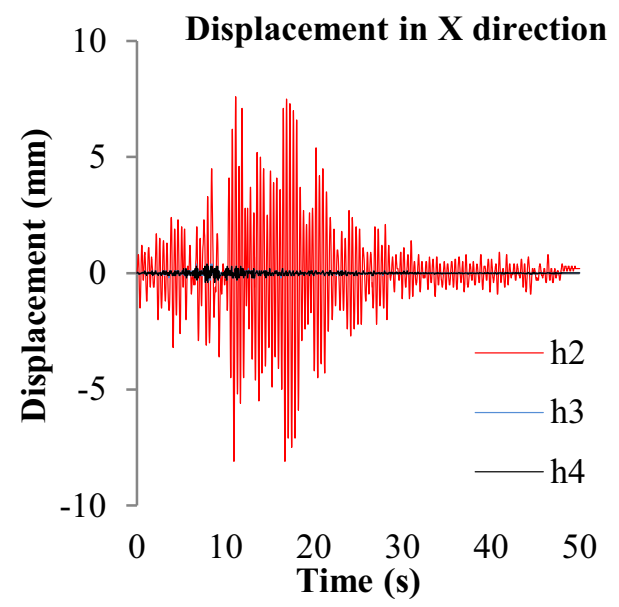

(c)

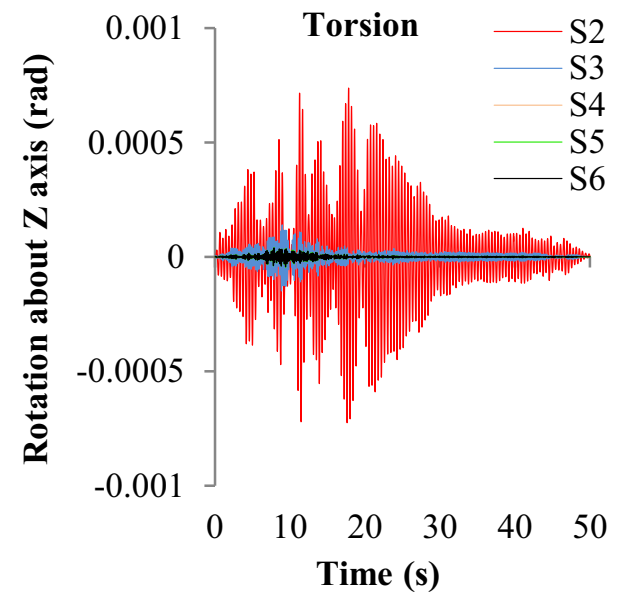

(a)

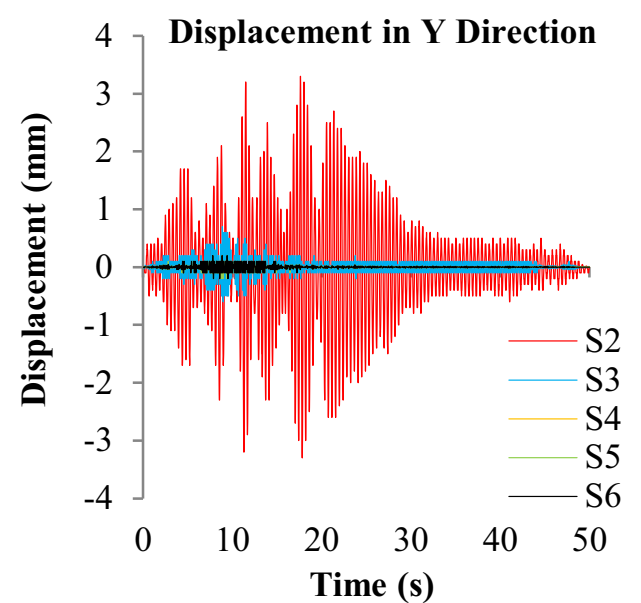

(b)

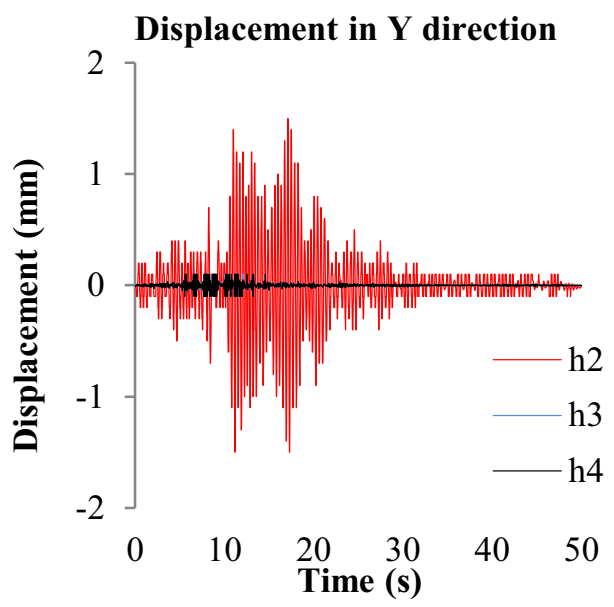

(d)

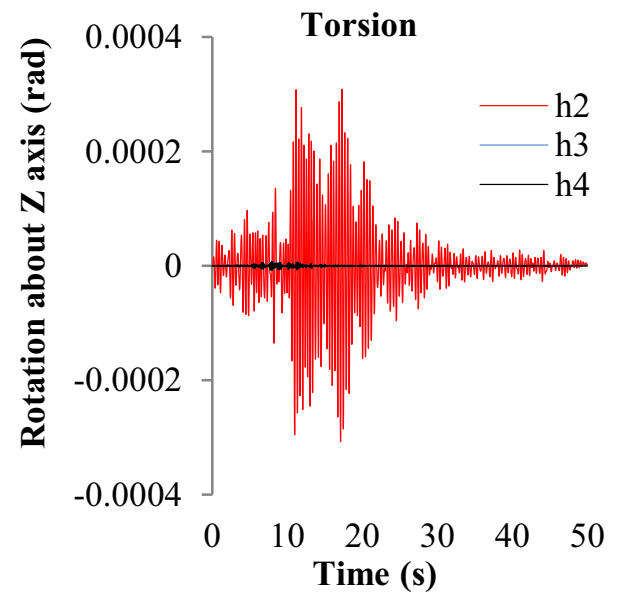

(b) 
zones and other type of soils. Soil-structure interaction is not considered here, which is another limitation of the study. Plan irregular structures like $\mathrm{T}$ and $\mathrm{L}$ shape can also be analysed in sloping ground in future. Non-linear analysis is also not done; so, these limitations are included as the future scope of study.

Open Access This article is distributed under the terms of the Creative Commons Attribution 4.0 International License (http://crea tivecommons.org/licenses/by/4.0/), which permits unrestricted use, distribution, and reproduction in any medium, provided you give appropriate credit to the original author(s) and the source, provide a link to the Creative Commons license, and indicate if changes were made.

\section{References}

Arjun S, Arathi S (2016) A Study on Dynamic Characteristics of RC Buildings on Hill slopes. Int J Sci Res (IJSR) 5(7):1116-1119

Birajdar BG, Nalawade SS (2004) Seismic Analysis of Buildings Resting On Sloping Ground. 13th World Conference on Earthquake Engineering, Vancouver, B.C., Canada, 1(6)

Ghosh R, Debbarma R (2015) Seismic Vulnerability Assessment of RC Framed Building with Soft Ground Storey. Int J Eng Technol Manag Appl Sci 3:116-125

Ghosh R, Debbarma R (2016) Seismic Vulnerability Assessment of Soft Storeyed Structures with Plan Irregularity and Collapse Prevention. Int J Eng Res Technol (IJERT) 5(1):755-761
Halkude SA, Kalyanshetti MG, Ingle VD (2013) Seismic Analysis of Buildings Resting on Sloping Ground with Varying Number of Bays and Hill Slopes. Int $J$ Eng Res Technol (IJERT) 2(12):3632-3640

Kalsulkar N, Rathod S (2015) Seismic Analysis of RCC Building Resting on Sloping Ground with varying Number of Bays and Hill Slopes. Int J Curr Eng Technol 5(3):2063-2069

Kaushik HB, Rai DC, Jain SK (2007) Stress-Strain characteristics of clay brick masonry under uniaxial compression. J Mater Civ Eng ASCE 19(9):728-739

Khadiranaikar RB, Masali A (2014) Seismic performance of buildings resting on sloping ground-a review. IOSR J Mech Civ Eng (IOSR-JMCE) 11(3):12-19

Konakalla R, Chilakapati RD, Raparla HB (2014) Effect of Vertical Irregularity in Multi-Storied Buildings Under Dynamic Loads Using Linear Static Analysis. Int J Educ Appl Res 5(2):29-34

Kumar S, Garg V, Sharma A (2014) Effect of Sloping Ground on Structural Performance of RCC Building under Seismic Load. Int J Sci Eng Technol 2(6):1310-1321

Murthy CVR (2006) Open Ground Storey RC Frame Buildings with $230 \mathrm{~mm}$ Columns unsafe during Earthquakes. Published in the National Seminar on Seismic detailing of R.C.C structures proceedings. pp 1-30

Nagarjuna R, Patil SB (2015) Lateral stability of multi storey building on sloping ground. Int Res J Eng Technol (IRJET) 2(4):1662-1669

Prashant D, Kori JG (2013) Seismic Response of one way slope RC frame building with soft storey. Int J Emerg Trends Eng Dev 5(3):311-320

Thombre P, Makarande SG (2016) Seismic analysis of building resting on sloping ground. J Emerg Technol Innov Res (JETIR) 3(6):296-300 